\title{
Saga of ghrelin: its structure, actions, and therapeutic uses
}

\author{
Wilma Delphine Silvia CR ${ }^{\mathrm{a}}$, Bharat Kumar PV \\ ${ }^{a}$ Department of Biochemistry, Sapthagiri Institute of Medical Sciences and Research Centre, \\ Bangalore-560090, India; ${ }^{b}$ Department of Biochemistry, Vydehi Institute of Medical Sciences and \\ Research Centre, Bangalore-560066, India
}

\begin{abstract}
The fat-regulating hormones, adiponectin, ghrelin, and leptin have been studied extensively because therapeutic modality might be gleaned from their augmentation or blockade. Since a link between the hormone and control of hunger was found, ghrelin levels in the human body have received a great deal of attention over the past several years. This mini-review summarizes the role of ghrelin, describing its actions and therapeutic uses.
\end{abstract}

Keywords: Adipocytes, ageing, ghrelin, growth hormone

Obesity is a severely disabling and costly disease that has gained widespread attention [1]. It significantly increases the risk for various disorders. These include hypertension, dyslipidemia, non-insulin-dependent diabetes mellitus, coronary artery disease, stroke, gallbladder disease, gastroesophageal reflux disease, hypercholesterolemia, osteoarthritis, obstructive sleep apnea, and cancer [2].

In general, when we have stored enough fat, leptin tells us to stop eating. On the other hand, ghrelin tells us to eat and store fat. In ancient times, ghrelin helped us to prepare for the next famine. In modern times, however, it acts as the evil twin of leptin. In fact, leptin is produced primarily in fat tissue, and circulates generally in proportion to fat stores. It encourages people to stop eating when their fat cells are full. In this sense, leptin and ghrelin are considered "Ying" and "Yang" in Chinese traditional medicine [3]. In the regulation of energy homeostasis, they act through similar targets and have opposite actions.

Correspondence to: Dr. Wilma Delphine Silvia CR, Professor \& Head, Department of Biochemistry, Sapthagiri Institute of Medical Sciences and Research Centre, \#15, Chikkasandra, Hesaraghatta main Road, Bangalore 560090, Karnataka, India. E-mail: widel@rediffmail.com
Ghrelin was discovered by Japanese scientists and reported in 1999 [4]. The name is based on its role as a growth hormone-releasing peptide, with reference to the Proto-Indo-European root "ghre", meaning to grow. The name can also be viewed as an interesting (and incidental) "pun", too, as the initial letters of the phrase growth hormone-releasing give us "ghre" with "lin" as a usual suffix for some hormones (pronounced GRELL-in). Leptin is a hormone that suppresses the appetite. It was discovered in 1995.

Over the past several years, ghrelin levels in the human body have received a great deal of attention, since a link was found between the hormone and control of hunger. In this article, we outline the details of ghrelin, in particular, its role in energy homeostasis and its therapeutic uses.

\section{Production, molecular biology, and structure}

Ghrelin is one of the more exciting hormones discovered. It is the only hormone found to stimulate food intake in humans [5]. Circulating ghrelin is mainly produced by X/A-like cells of the oxyntic gastric mucosa [6]. Endogenous ghrelin production has also been localized to the small intestine, gastric mucosa, pancreas, hypothalamus, kidneys, pituitary gland, testis, 
ovary, placenta, lymphocytes, and brain [7-10]. The production of ghrelin in the stomach, which is higher in females, increases markedly in the immediate postnatal period [11], but declines thereafter [12].

The human ghrelin gene is located in chromosome 3. It is made up of four exons and three introns. The mature protein is encoded in exons 1 and 2 [13]. The 5 '-flanking region of the gene contains a non-functional TATATAA box and a ghrelin promoter that is activated by glucagon and c-AMP [14]. Some gastric tumor cell lines express the promoter, but others do not. This suggests that human ghrelin promoter may have cellspecific activity. The hnRNA of the gene transcript is processed by alternative splicing to yield two different mature mRNAs. One produces the ghrelin precursor, and the second yields des-Gln 14-ghrelin [15]. Ghrelin provides the first example of the production of two different mature biologically active peptides that result from the alternative splicing of a peptide-coding region.

The human ghrelin precursor (prepro-ghrelin) is composed of 117 amino acids, and the ghrelin sequence of 28 amino acids immediately follows the 23-residue signal peptide. Before being secreted, the ghrelin molecule undergoes an enzymatic process at the cytoplasm, an n-octanoyl addition at Ser 3. This esterification by n-octanoic acid, which is essential for the biological activity of ghrelin, yields the finally secreted peptide of 3315 molecular weight. This process of acylation has no precedent in cell biology either, being the first example of acylation in a secreted protein [16]. Hence, ghrelin circulates in two major forms, acylated (5\% of total ghrelin) and Desacylated/Unacylated ghrelin (UAG) (the form lacking n-octanoylation) is abundant (95\% of total ghrelin) in the circulation, but it does not bind to the GHS-R1a that stimulates growth hormone (GH) release. UAG is converted to ghrelin by the action of ghrelin O-acyl transferase (GOAT), a member of the membranebound O-acyl transferase family. This is expressed primarily in the stomach and specifically octanoylates the Ser3 residue of the ghrelin peptide. These two forms have potential differences in their metabolic effects [17].

The active binding core of the molecule consists of the first 4-5 amino acids including the acylated Ser 3 , short peptides containing this sequence efficiently bind to the growth hormone secretion (GHS) receptor but they are devoid of GH secretory capability [16].

Circulating ghrelin originates mainly in the stomach, and circulates at plasma concentrations of
$200-600 \mathrm{pg} / \mathrm{ml}$. The secretion of ghrelin during 24 hours correlates significantly with the values obtained in the basal state [18]. Half-life for acylated ghrelin in the circulation is approximately 30 minutes [19].

\section{Biological actions Growth hormone}

The ghrelin receptor was known well before ghrelin was discovered. Cells within the anterior pituitary bear a receptor to detect when Ghrelin is produced in the hypothalamic arcuate nucleus, and where it stimulates the secretion of growth hormone from the anterior pituitary gland. The receptor was named the growth hormone secretagouge receptor (GHS-R). The natural ligand for the GHS-R was announced in 1999 as "ghrelin" because of its ability to provoke GHS.

The GHS-R1a, a G protein coupled receptor, activates the phospholipase $\mathrm{C}$ signaling route leading to an intracellular $\mathrm{Ca}_{2}^{+}$rise. An active cross-talk at the somatotrope cell is maintained between the growth hormone releasing hormone (GHRH) and the ghrelin receptors in order to coordinate and potentiate the cell response expressed in the CNS. This is found at particularly high levels in the hypothalamus and peripheral tissues, including the pituitary, the gastrointestinal tract and adipose tissue [20].

\section{Energy homeostasis}

Adipogenesis is a highly controlled process, in which the expression of adipose-specific genes is crucial for inducing differentiation and for determining the phenotypic characteristics of adipocytes [21]. The main transcription factors that control this process include PPARg (peroxisome proliferator- activated receptor g) and SREBP1 (sterol-regulatory element binding protein-1). Differentiated adipocytes take up free fatty acids (FFAs) and glycerol for the biosynthesis of triglycerides. Acylated ghrelin has been shown to increase adiposity in rats by enhancing the expression of fat-storage enzymes, such as lipoprotein lipase (LPL), acetyl-CoA carboxylase (ACC), fatty acid synthase (FAS) and stearoyl-CoA desaturase-1, through centrally mediated mechanisms [22]. Moreover, it has been suggested that acylated ghrelin directly acts on adipocytes for stimulating adipogenesis in rodents [23].

Ghrelin and adenosine 5'-monophosphate activated protein kinase. Adenosine 5'monophosphate activated protein kinase (AMPK) 
energy homeostasis [24], and it mediates some of the effects of adipocyte hormones including ghrelin, leptin, and adiponectin. Increasing evidence shows that AMPK plays a central role in the appetite modulating and metabolic effects of Ghrelin. Ghrelin increases appetite by AMPK phosphorylation stimulating production of orexigenic neuropeptide Y/agoutirelated protein by cells in the arcuate nucleus. Pharmacological administration of ghrelin induces a positive energy balance, increasing body weight. Recent studies increased understanding of the upstream regulation of neuropeptide Y/agouti-related protein signaling and the central control of adipocyte metabolism [25]. In addition, high levels of ghrelin have been found to suppress the amount of fat used by the adipose tissue. This implies that those with high levels of ghrelin in their bodies will not only feel hungrier than those with low level will, but may burn fat more slowly as well. Tschop et al. [26] have also shown that daily peripheral administration of ghrelin can stimulate adiposity in rats without influencing food intake. It is possible that the direct effects of ghrelin on adipose tissue are responsible for this increase in fat mass.

Plasma ghrelin levels rise during fasting and fall rapidly after a meal. Fasting circulating ghrelin concentrations are inversely correlated with body weight and fall following weight loss in humans. Calorie intake appears to be the primary regulator of plasma ghrelin levels, but the exact mechanisms mediating ghrelin release are unknown. Ghrelin antagonists may treat excessive food intake. Glucose and/or insulin have been reported to suppress ghrelin release [27]. However, another study has shown that physiological concentrations of glucose or insulin have little effect on plasma ghrelin levels [28]. There is evidence to support a role for ghrelin in enhancing insulin sensitivity and ghrelin has been reported to stimulate insulin secretion [29]. Growth hormone is an anabolic hormone, sparing protein stores at the expense of fat during conditions of caloric restriction. Ghrelin also inhibits production of anorectic proinflammatory cytokines [30]. Thus, ghrelin exhibits anti-catabolic actions through both growth hormonedependent and independent mechanisms.

\section{Therapeutic uses Ageing}

Ageing is associated with progressive decrease in GHS, appetite and energy intake [31]. Ghrelin may have therapeutic potential to assist in the recovery of frail patients who require both nutritional support and conventional rehabilitation [32].

\section{Sleep}

Ghrelin itself has recently been reported to be a sleep-promoting factor in humans. Similarly to GHRH, repetitive i.v, ghrelin administration enhanced SWS, and slowed wave activity (SWA) and GH in young normal males [33]. In a recent study, sleep EEG and the nocturnal levels of ghrelin were examined simultaneously. A trend was found suggesting a lower time spent in stage I sleep in subjects with high nocturnal ghrelin levels [34].

\section{Cancers}

Anorexia, frequently encountered in cancer patients, is a major cause of malnutrition and cachexia in this patient population. An acute, randomized, placebo-controlled, crossover clinical trial was performed to determine whether ghrelin could stimulate appetite in seven cancer patients with anorexia. A marked increase in energy intake was observed after ghrelin infusion in comparison with saline control individuals; all patients in the study exhibited increased food consumption. The meal appreciation score was also higher in ghrelin treated individuals [35].

\section{Gastrointestinal disorders}

It also suppresses the pro-inflammatory mechanisms and augments anti-inflammatory mechanisms thus creating a possibility of its therapeutic use in various gastrointestinal inflammatory conditions including colitis, ischemia reperfusion injury and sepsis. In fact, animal models of colitis, ischemia re-perfusion, and sepsis related gut dysfunction have been shown to be benefit with therapeutic doses of ghrelin [36].

\section{Metabolic syndrome}

Ghrelin level is decreased in patients with metabolic syndrome and patients with polycystic ovarian syndrome, in accordance with the negative correlation between ghrelin and body weight. In the cases of diabetes mellitus type 1 and type 2, the level of ghrelin is generally decreased and the response of ghrelin after meal consumption is attenuated or remains similar with normal people [37-39]. 


\section{Vaccine}

Recently, scientists have developed an anti-obesity vaccine, which is directed against the hormone ghrelin. This prevents ghrelin from reaching the central nervous system, thus producing a desired reduction in weight gain [40].

\section{Cardiovascular disorders}

Ghrelin has several cardiovascular effects, as indicated by the presence of its receptor in blood vessels and ventricles of the heart. Infusion of ghrelin decreases systemic vascular resistance and increases cardiac output in patients with heart failure. Furthermore, repeated administration of ghrelin improves cardiac structure and function, and attenuates the development of cardiac cachexia in rats with heart failure. These results suggest that ghrelin has therapeutic potential in the treatment of severe chronic heart failure [41].

\section{Chronic gastroduodenal ulcers}

Experimental evidences have shown that treatment with ghrelin accelerates healing of chronic gastroduodenal ulcers and this effect is mediated by the release of endogenous GH and Insulin like growth factor-1 [42].

\section{Chronic constriction injury (CCI)}

Ghrelin has been shown to have anti-nociceptive activity and anti-inflammatory properties by decreasing pro-inflammatory cytokines. The protective effect by ghrelin in the spinal cord is mediated through the suppression of TNF-alpha and IL-1beta. Thus, ghrelin may be a promising peptide in the management of neuropathic pain [43].

\section{Growth hormone deficiency}

Ghrelin may be applied to the diagnosis and treatment of GH deficiency. Because of its potent GH-releasing activity and specificity, intravenous injection of Ghrelin into humans does not show any side effects, suggesting that ghrelin may be useful for diagnosing GH deficiency. Adult and child GH deficiency may be benefitted by ghrelin treatment. The GH-releasing activity of ghrelin is comparable to that of GHRH [44, 45].

\section{Conclusion}

The discovery of ghrelin O-acyltransferase has opened new research opportunities that could lead to major understanding of ghrelin physiology. Many studies have attempted to elucidate the various activities of ghrelin. These studies may lend support to the development of novel clinical applications for ghrelin in the treatment of various disorders, particularly cachexia, anorexia, and ageing.

\section{Acknowledgements}

The authors thank Mr. Vincent Sunil Kumar, Sherwin Vishesh Jathanna, and Shilpa for their help in publishing this article. The authors have no conflict of interest to report.

\section{References}

1. DeJong G, Sheppard L, Lieber M, Chenoweth D. The cost of being couch potato. Mich Health Hosp. 2003; 39:24.

2. Allison DB, Fontaine KR, Manson JE, Stevens J, Van Itallie TB. Annual deaths attributable to obesity in the United States. JAMA. 1999; 282:1530-8.

3. Zigman JM, Elmquist JK. Minireview: from anorexia to obesity - the Yin and Yang of body weight control. Endocrinol. 2003; 144: 3749-56.

4. Kojima M, Hosoda H, Date Y, Nakazato M, Matsuo H, Kangawa K. Ghrelin is a growth-hormone-releasing acylated peptide from stomach. Nature. 1999; 402: 656-60.

5. Espelund U, Hansen T, Orskov H, Frystyk J. Assessment of ghrelin. APMIS Suppl. 2003; 109: 140-5.

6. Date Y, Kojima M, Hosoda H, Sawaguchi A, Mondal MS, Suganuma T, et al. Ghrelin, a novel growth hormone-releasing acylated peptide, is synthesized in a distinct endocrine cell type in the gastrointestinal tracts of rats and humans. Endocrinol. 2000; 141: 4255-61.

7. Holdstock C, Engstrom B, Ohrvall M, Lind L, Sundbom M, Karlsson F. Ghrelin and adipose tissue regulatory peptides: effect of gastric bypass surgery in obese humans. J Clin Endocrinol Metab. 2003; 88: 3177.

8. Tanaka M, Hayashida Y, Nakao N, Nakai N, Nakashima K. Testis-specific and developmentally induced expression of a ghrelin gene-derived transcript that encodes a novel polypeptide in the mouse. Biochim Biophys Acta. 2001; 1522: 62-5.

9. Caminos JE, Tena-Sempere M, Gaytan F, SanchezCriado JE, Barreiro ML, Nogueiras R, et al. Expression of ghrelin in the cyclic and pregnant rat ovary. Endocrinol. 2003;144:1594-602. 
10. Gualillo O, Caminos JE, Kojima M, Kangawa K, Arvat E, Ghigo E, et al. Gender and gonadal influences on ghrelin mRNA levels in rat stomach. Eur J Endocrinol. 2001;144: 687-90.

11. Sakata I, Tanaka T, Matsubara M, Yamazaki M, Tani S, Hayashi Y, et al. Postnatal changes in ghrelin mRNA expression and in ghrelin-producing cells in the rat stomach. J Endocrinol. 2002; 174:463-71.

12. Liu YL, Yakar S, Otero-Corchon V, Low MJ, Liu J-L. Ghrelin gene expression is age-dependent and influenced by gender and the level of circulating IGF-1. Mol Cell Endocrinol. 2002; 189: 97-103.

13. Wajnrajch MP, Ten IS, Gertner JM, Leibel RL. Genomic organization of the human GHRELIN gene. J Endocr Genet. 2000; 1:231-3.

14. Kishimoto M, Okimura $Y$, Nakata H, Kudo T, Iguchi G, Takahashi Y, et al. Cloning and characterization of the 5'-flanking flanking region of the human ghrelin gene. Biochem Biophys Res Comm. 2003; 305:186-92.

15. Hosoda H, Kojima M, Matsuo H, Kangawa K. Purification and characterization of rat des-Gln14Ghrelin, a second endogenous ligand for the growth hormone secretagogue receptor. J Biol Chem. 2000; 275: 21995-2000.

16. Casanueva FF, Dieguez C. Ghrelin: the link connecting growth with metabolism and energy homeostasis. Rev Endocrine Metab Dis. 2002; 3:325-38.

17. Hosoda H, Kojima M, Matsuo H, Kangawa K. Ghrelin and des-acyl ghrelin: two major forms of rat ghrelin peptide in gastrointestinal tissue. Biochem Biophys Res Commun. 2000; 279:909-13.

18. Cummings DE, Purnell JQ, Frayo RS, Schmidova K, Wisse BE, Weigle DS. A preprandial rise in plasma ghrelin levels suggests a role in meal initiation in humans. Diabetes. 2001; 50:1714-19.

19. Tolle V, Bassant M-H, Zizzari P, Poindessous-Jazat F, Tomasetto C, Epelbaum J, et al. Ultraian rhythmicity of ghrelin secretion in relation with $\mathrm{GH}$, feeding behaviour, and sleep-wake patterns in rats. Endocrinol. 2002; 143:1353-61.

20. Petersenn S. Structure and regulation of the growth hormone secretagogue receptor. Minerva Endocrinol. 2002; 27:243-56.

21. Rosen ED, MacDougald OA. Adipocyte differentiation from the inside out. Nat Rev Mol Cell Biol. 2006; 7: 885-96.

22. Theander-Carrillo C, Wiedmer P, Cettour-Rose P, Nogueiras R, Perez-Tilve D, Pfluger P, et al. Ghrelin action in the brain controls adipocyte metabolism. J Clin Invest. 2006; 116:1983-93.
23. Choi K, Roh SG, Hong YH, Shrestha YB, Hishikawa D, Chen $\mathrm{C}$, et al. The role of ghrelin and growth hormone secretagogues receptor on rat adipogenesis. Endocrinology. 2003; 144:754-9.

24. Kola B, Boscaro M, Rutter GA, Grossman AB, Korbonits M. Expanding role of AMPK in endocrinology. Trends Endocrinol Metab. 2006; 17: 205-15.

25. Kojima M, Kangawa K. Ghrelin: structure and function. Physiol Rev. 2005; 85:495-522.

26. Tschop M, Smiley DL, Heiman ML. Ghrelin induces adiposity in rodents. Nature. 2000; 407: 908-13.

27. Yoshihara F, Kojima M, Hosoda H, Nakazato M, Kangawa K. Ghrelin: a novel peptide for growth hormone release and feeding regulation. Curr Opin Clin Nutr Metab Care. 2002; 5:391-5.

28. Schaller G, Schmidt A, Pleiner J, Woloszczuk W, Wolzt M, Luger A. Plasma ghrelin concentrations are not regulated by glucose or insulin: a double-blind, placebo-controlled crossover clamp study. Diabetes. 2003; 52:16-20.

29. Lee HM, Wang G, Englander EW, Kojima M, Greeley Jr GH. Ghrelin, a new gastrointestinal endocrine peptide that stimulates insulin secretion: enteric distribution, ontogeny, influence of endocrine, and dietary manipulations. Endocrinology. 2002; 143: 185-90.

30. Dixit VD, Schaffer EM, Pyle RS, Collins GD, Sakthivel SK, Palaniappan R, et al. Ghrelin inhibits leptin- and activation induced proinflammatory cytokine expression by human monocytes and T cells. J Clin Invest. 2004; 114:57-66.

31. Corpas E, Harman SM, Blackman MR. Human growth hormone and human aging. Endocr Rev. 1993; 14: 20-39.

32. Bach MA, Rockwood K, Zetterberg C, Thamsborg G, Hebert R, Devogelaer JP, et al. The effects of MK0677, an oral growth hormone secretagogue, in patients with hip fracture. J Am Geriatr Soc. 2004; 52: 516-23.

33. Weikel JC, Wichniak A, Ising M. Ghrelin promotes slow-wave sleep in humans. Am J Physiol Endocrinol Metab. 2003; 284:407-15.

34. Schuessler P, Uhr M, Ising M, Schmid D, Weikel J, Steiger A. Nocturnal ghrelin levels - relationship to sleep EEG, the levels of growth hormone, ACTH and cortisol- and gender differences. J Sleep Res. 2005; 14: 329-36.

35. Neary NM, Small CJ, Wren AM, Lee JL, Druce MR, Palmieri C, et al. Ghrelin increases energy intake in 
cancer patients with impaired appetite: acute, randomized, placebocontrolled trial. J Clin Endocrinol Metab. 2004; 89:2832-6.

36. Gonzalez-Rey E, Chorny A, Delgado M. Therapeutic action of ghrelin in a mouse model of colitis. Gastroenterology. 2006; 130:1707-20.

37. Ukkola O, Poykko SM, Kesaniemi YA. Low plasma ghrelin concentration is an indicator of the metabolic syndrome. Ann Med. 2006; 38: 274-9.

38. Barber TM, Casanueva FF, Karpe F, Lage M, Franks S, McCarthy MI, Wass JAH. Ghrelin levels are suppressed and show a blunted response to oral glucose in women with polycystic ovary syndrome. Eur J Endocrinol. 2008; 158:511-6.

39. Pusztai P, Sarman B, Ruzicska E, Toke J, Racz K, Somogyi A, et al. Ghrelin: a new peptide regulating the neurohormonal system, energy homeostasis and glucose metabolism. Diabetes Metab Res Rev. 2008; 24:343-52.

40. Zorrilla EP, Iwasaki S, Moss JA, Chang J, Otsuji J, Inoue K, et al. Vaccination against weight gain. Proc Natl Acad Sci USA. 2006; 103:13226-31.
41. Nagaya N, Kangawa K. Ghrelin improves left ventricular dysfunction in cardiac cachexia in heart failure. Curr Opin Pharmacol. 2003; 3:146-51.

42. Ceranowicz P, Warzecha Z, Dembinski A, Sendur R, Cieszkowski J, Ceranowicz D, et al. Treatment with ghrelin accelerates the healing of acetic acid-induced gastric and duodenal ulcers in rats. J Physiol Pharmacol. 2009; 60: 87-98.

43. Guneli E, Onal A, Ates M, Bagriyanik HA, Resmi H, Orhan CE, et al. Effects of repeated administered ghrelin on chronic constriction injury of the sciatic nerve in rats. Neurosci Lett. 2010; 479:226-30.

44. Baldelli R, Otero XL, Camina JP, Gualillo O, Popovic V, Dieguez C, et al. Growth hormone secretagogues as diagnostic tools in disease states. Endocrine. 2001; 14:95-9.

45. Thorner MO, Chapman IM, Gaylinn BD, Pezzoli SS, Hartman ML. Growth hormone-releasing hormone and growth hormone-releasing peptide as therapeutic agents to enhance growth hormone secretion in disease and aging. Recent Prog Horm Res. 1997; 52: 215-44. 